\title{
Comfort studies of rail passengers
}

\author{
J. F. NICOL, C. DORÉ, J. S. WEINER, D. E. LEE, S. P. PRESTIDGE, \\ and M. J. ANDREWS \\ National Institute of Medical Research, Hampstead NW3, MRC Environmental Physiology Unit, \\ London School of Hygiene and Tropical Medicine, London WC1 and British Railways \\ Southern Region, Croydon
}

\begin{abstract}
Nicol, J. F., Doré, C., Weiner, J. S., Lee, D. E., Prestidge, S. P., and Andrews, M. J. (1973). British Journal of Industrial Medicine, 30, 325-334. Comfort studies of rail passengers. A short series of trials is described in which a specimen car of the new High Density Rolling Stock was laden with passengers at different densities and under different environmental constraints, designed to simulate 'shut-down' conditions.

The results suggest that the limit for comfort, $21 \cdot 8^{\circ} \mathrm{C}$ corrected effective temperature (CET), proposed by Bell and Watts (1971) is reasonable but that temperatures some 3 or $4^{\circ} \mathrm{C}$ higher can be tolerated without undue discomfort.

The physiological limit for safety recommended by Bell and Watts is a CET of $30 \cdot 6^{\circ} \mathrm{C}$. This will be reached in less than 20 minutes if there is a power failure in warm conditions in crowded trains.

An undesirable, possibly dangerous, level of discomfort will be experienced by passengers in ventilated but crowded trains after 30 minutes.

In any case it is recommended that the globe temperature in a carriage should not exceed $30^{\circ} \mathrm{C}$.
\end{abstract}

From their survey of the literature, Bell and Watts (1971) recommended that for summertime comfort an upper indoor temperature limit of $21.8^{\circ} \mathrm{C}$ corrected effective temperature (CET) was desirable. This limit was based on the criterion that at this temperature only $20 \%$ of persons exposed should feel uncomfortable while doing light sedentary tasks. For a $40 \%$ discomfort criterion Bell and Watts stated that the limit could be increased by $2^{\circ} \mathrm{C}$.

Bell and Watts also pointed out that at a level as high as $30.6^{\circ} \mathrm{C} \mathrm{CET}$, body temperature regulation is not impaired, but of course such conditions, though not dangerous physiologically nor detrimental to the performance of moderate physical work, will fall outside the comfort zone. What, however, is not clear is the intensity of subjective distress that this condition would cause and for how long subjects would be prepared to endure it in everyday circumstances.

A situation of this kind, it is believed, might affect passengers in the new British Rail High
Density Rolling Stock on warm days if the ventilation system were to fail. The present design of the rolling stock does not allow for natural ventilation.

Information on the way in which passengers would react when temperature conditions rose to levels between 22 and $30^{\circ} \mathrm{C}$ was therefore required.

In this paper a short series of trials is described in which a specimen car of the new High Density Rolling Stock was laden with passengers at different densities and under different environmental constraints, designed to simulate these 'shut-down' conditions. The reactions to the environments of the passengers are given and recommendations are made.

\section{The trials}

\section{Subjects}

In all, 80 subjects were used, 67 men and 13 women. All were volunteers from British Rail clerical and administrative staff. Table 1 gives physical data for the subjects. Subjects taking part in the trials were asked to wear one of two weights of clothing. All were asked to come with 
TABLE 1

Physical Data on Subjects

\begin{tabular}{|c|c|c|c|c|}
\hline \multicolumn{2}{|c|}{ Subjects } & $\begin{array}{l}\text { Age } \\
(y r)\end{array}$ & $\begin{array}{l}\text { Weight } \\
(l b)\end{array}$ & $\begin{array}{c}\text { Height } \\
\text { (in) }\end{array}$ \\
\hline Men & $\begin{array}{l}\operatorname{Max} \ldots \\
\operatorname{Min} \ldots \\
\text { Mean }\end{array}$ & $\begin{array}{l}62 \\
16 \\
34 \cdot 7\end{array}$ & $\begin{array}{l}203 \\
112 \\
159 \cdot 5\end{array}$ & $\begin{array}{l}78 \\
60 \\
69 \cdot 8\end{array}$ \\
\hline Women (13) & $\begin{array}{l}\operatorname{Max} \ldots \\
\operatorname{Min} \ldots \\
\text { Mean }\end{array}$ & $\begin{array}{l}56 \\
18 \\
29 \cdot 9\end{array}$ & $\begin{array}{c}161 \\
91 \\
133 \cdot 2\end{array}$ & $\begin{array}{l}70 \\
58 \\
64 \cdot 8\end{array}$ \\
\hline (80) & $\begin{array}{l}\operatorname{Max} \ldots \\
\text { Min } \ldots \\
\text { Mean }\end{array}$ & $\begin{array}{l}62 \\
16 \\
33 \cdot 8\end{array}$ & $\begin{array}{c}203 \\
91 \\
155 \cdot 1\end{array}$ & $\begin{array}{l}78 \\
58 \\
68 \cdot 9\end{array}$ \\
\hline
\end{tabular}

jackets (men) or cardigans. During the trials half were asked to wear these and half to discard them.

\section{Conditions}

The trials were carried out on 29 September 1971. Three tests were made in an unheated carriage with its windows blacked out. The carriage was in a heated shed. In all trials 36 subjects were seated and the remainder stood.

Trial A (a.m.) Low density loading, 45 subjects, 9 standing Temperature in shed $20.0^{\circ} \mathrm{C}$ (exceeded on approximately 65 days per annum in southern England)

Trial B (p.m.) High density loading, 78 subjects, 42 standing. Because of the sharp initial rise in temperature, ventilation fans were switched on after 10 minutes of occupation. Temperature in shed $23.5^{\circ} \mathrm{C}$ (exceeded on approximately 30 days per annum)

Trial C (p.m.) High density loading, 78 subjects, 42 standing. As far as possible, subjects who stood in run B sat in run $\mathrm{C}$, and vice versa. The temperature was allowed to run wild except that the fans were put on for half a minute after 18 minutes to avoid dangerous overheating. The run was abandoned after 30 minutes. Temperature in shed $23 \cdot 5^{\circ} \mathrm{C}$.

The CET and globe thermometer temperature (TG) in each of the trials are shown in Figure 1. It will be noted that, when the fans are put on, the drop in CET is greater than that in TG. The enormous build-up of water vapour in the air is soon exhausted by the fans. CET is sensitive to this drop in humidity.

The conditions encountered in each of the three trials approximate those which might be met under field conditions.

Trial A approximates breakdown with a loss of power and a low density of passengers.

Trial B, after the first 10 minutes, approximates the equilibrium condition in a crowded carriage ventilated normally.

Trial $\mathbf{C}$ approximates the breakdown condition in a crowded train.

\section{Instrumentation}

Temperatures were recorded in space $B$ and space $C$ (Fig. 2). The temperature recorders were WBGT instruments which measure wet and dry bulb as well as globe temperature. They were suspended at standing head

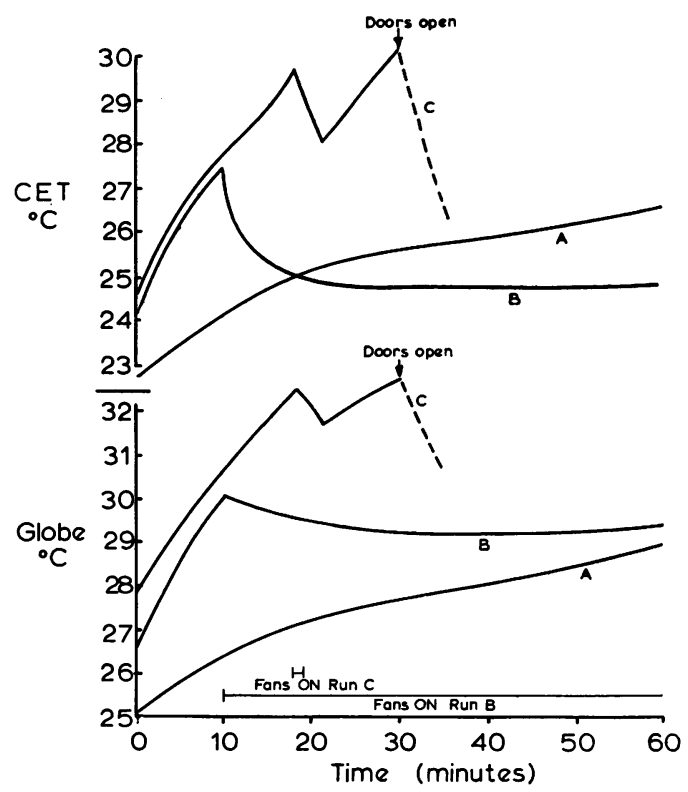

FIG. 1. Temperatures in the three runs.

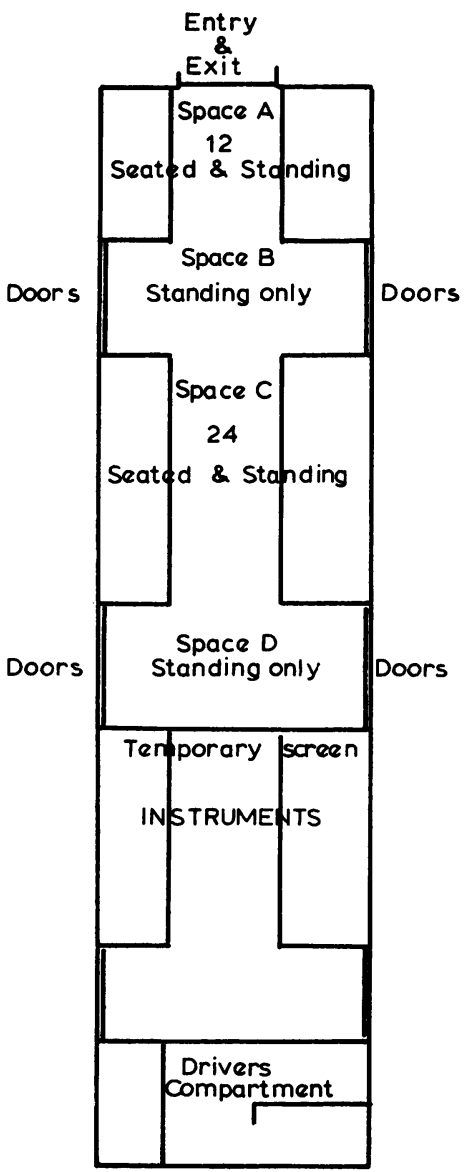

FIG. 2. Diagram of carriage. 
level. They were read at 4-minute intervals throughout the period of the trials.

\section{Questionnaires}

For each trial each subject was asked to fill in a questionnaire at the start of the trial and at 15-minute intervals thereafter. This means that five questionnaires (see Appendix A) were filled in by each subject for trials A and $B$, and three for trial $C$. On each questionnaire there were seven questions, each of which the subjects answered according to the scale supplied.

Comfort and hotness are deliberately separated in the manner of Gagge, Stolwijk, and Hardy (1967) as it was felt that, in the conditions of the experiment, dimensions of discomfort other than hotness would be important. The apparent hotness of the air was felt to be important as passengers might take this, rather than their own personal feeling of hotness, as a criterion of the adequacy of the conditions of the carriage. Trunk and foot hotness are separately assessed.

Skin moisture, alertness, and the tiredness of the legs (of standing subjects) are also included as factors which might be related to temperature and which would therefore have a bearing on comfort and the general adequacy of the accommodation. The scale of skin moisture is one which has been used in studies in the tropics (Nicol, 1973). The scales of alertness and tiredness were designed to be comparable with the other scales.

\section{Results}

\section{Answers to questionnaires}

Figure 3 shows the proportions of the subjects who answered the questions in terms of each scale on the different occasions during each trial. For each occasion a histogram running from 0 to $100 \%$ is divided up to show the relative proportions of respondents giving each of the answers to the seven questions.

Table 2 gives the mean values of each of the subjective votes on each occasion.

In general, the conditions can be seen, from Table
2 and Fig. 3, to be becoming subjectively more severe as time progresses in each of the trials. The drop in apparent hotness of the air (Q2) at 15 minutes in trial B is probably caused by the sudden drop in humidity caused by switching on the ventilation. All the scales seem to react to the very severe conditions of trial C, scales 6 and 7 being least affected.

A probit analysis of the answers to questions 3a (hotness of trunk) and 4 (comfort) in relation to CET yielded the curves given in Figure 4. These show the percentage of subjects who reply 'warm' or 'hot' on scale 3a and 'slightly uncomfortable', 'uncomfortable' or 'very uncomfortable' on scale 4 as a function of temperature.

\section{Relationships between the variables}

Tables 3 and 4 are the correlation matrices for sitting and standing subjects showing the intercorrelation between the subjective variables and between these and the three temperature indices and the time of exposure. The temperatures used are CET, TG, and air temperature (TA). Time is expressed as the time after the beginning of each trial.

From the tables it is clear that there is little to choose between the different temperature indices as predictors of the subjective scales, except that TG seems somewhat less satisfactory in the prediction of the subjective hotness of the air than do CET and TA.

Not unexpectedly, leg tiredness is correlated better with time than with temperature. Alertness is also somewhat more closely related to time than to temperature.

The subjective scales appear to fall into three groups-(1) the three 'hotness' scales (air, trunk, foot), (2) comfort and moisture, (3) alertness and leg tiredness. The hotness group are highly intercorrelated with each other and hardly correlate with

TABLE 2

Values of Cet and TG for Each Occasion in the Trials: Mean Vote on Each Subjective Scale

\begin{tabular}{|c|c|c|c|c|c|c|c|c|c|c|c|c|c|c|c|}
\hline \multicolumn{3}{|c|}{ Variable } & \multicolumn{5}{|c|}{ Trial $A$} & \multicolumn{5}{|c|}{ Trial $B$} & \multicolumn{3}{|c|}{ Trial $C$} \\
\hline $\begin{array}{l}\text { Occasion } \\
\text { Time from sta } \\
\text { (min) }\end{array}$ & frial & . & $\begin{array}{l}1 \\
0\end{array}$ & $\begin{array}{l}2 \\
15\end{array}$ & $\begin{array}{c}3 \\
30\end{array}$ & $\begin{array}{r}4 \\
45\end{array}$ & $\begin{array}{l}5 \\
60\end{array}$ & $\begin{array}{l}6 \\
0\end{array}$ & $\begin{array}{c}7 \\
15\end{array}$ & $\begin{array}{c}8 \\
30\end{array}$ & $\begin{array}{r}9 \\
45\end{array}$ & $\begin{array}{l}10 \\
60\end{array}$ & $\begin{array}{l}11 \\
0\end{array}$ & $\begin{array}{l}12 \\
15\end{array}$ & $\begin{array}{l}13 \\
30\end{array}$ \\
\hline $\begin{array}{l}\text { CET }\left({ }^{\circ} \mathrm{C}\right) \ldots \\
\text { TG }\left({ }^{\circ} \mathrm{C}\right) \ldots\end{array}$ & . & $\begin{array}{l}\cdots \\
\cdots\end{array}$ & $\begin{array}{l}22 \cdot 9 \\
25 \cdot 3\end{array}$ & $\begin{array}{l}24 \cdot 6 \\
26 \cdot 8\end{array}$ & $\begin{array}{l}25 \cdot 6 \\
27 \cdot 7\end{array}$ & $\begin{array}{l}26 \cdot 1 \\
28 \cdot 3\end{array}$ & $\begin{array}{l}26 \cdot 6 \\
28 \cdot 7\end{array}$ & $\begin{array}{l}24 \cdot 5 \\
27 \cdot 0\end{array}$ & $\begin{array}{l}25 \cdot 2 \\
29 \cdot 5\end{array}$ & $\begin{array}{l}24 \cdot 8 \\
29 \cdot 2\end{array}$ & $\begin{array}{l}24 \cdot 8 \\
29 \cdot 0\end{array}$ & $\begin{array}{l}24 \cdot 9 \\
29 \cdot 3\end{array}$ & $\begin{array}{l}24 \cdot 8 \\
28 \cdot 1\end{array}$ & $\begin{array}{l}28 \cdot 7 \\
31 \cdot 5\end{array}$ & $\begin{array}{l}30 \cdot 1 \\
32 \cdot 6\end{array}$ \\
\hline $\begin{array}{l}\text { Mean answer } \\
\text { to question } \\
\text { for } \\
\text { occasion }\end{array}$ & $\begin{array}{l}2 \\
3 \mathrm{a} \\
3 \mathrm{~b} \\
4 \\
5 \\
6 \\
7\end{array}$ & $\begin{array}{l}\ldots \\
\ldots \\
\ldots \\
\ldots \\
\ldots \\
\ldots\end{array}$ & $\begin{array}{l}2 \cdot 80 \\
3 \cdot 53 \\
3 \cdot 86 \\
3 \cdot 84 \\
3 \cdot 76 \\
3 \cdot 60 \\
3 \cdot 89\end{array}$ & $\begin{array}{l}2.13 \\
2.64 \\
3.03 \\
3.64 \\
3.49 \\
3.49 \\
3.44\end{array}$ & $\begin{array}{l}1 \cdot 96 \\
2 \cdot 27 \\
2 \cdot 50 \\
3 \cdot 38 \\
3 \cdot 22 \\
3 \cdot 27 \\
3 \cdot 33\end{array}$ & $\begin{array}{l}1 \cdot 75 \\
2 \cdot 18 \\
2 \cdot 20 \\
3 \cdot 24 \\
3 \cdot 16 \\
2 \cdot 96 \\
3 \cdot 00\end{array}$ & $\begin{array}{l}1.67 \\
2.02 \\
2.14 \\
3.22 \\
2.98 \\
2.84 \\
2.67\end{array}$ & $\begin{array}{l}2 \cdot 04 \\
2 \cdot 36 \\
2 \cdot 52 \\
3 \cdot 38 \\
3 \cdot 34 \\
3 \cdot 46 \\
3 \cdot 76\end{array}$ & $\begin{array}{l}2 \cdot 68 \\
2 \cdot 40 \\
2 \cdot 32 \\
3 \cdot 37 \\
3 \cdot 21 \\
3 \cdot 38 \\
3 \cdot 48\end{array}$ & $\begin{array}{l}2 \cdot 22 \\
2 \cdot 22 \\
2 \cdot 08 \\
3 \cdot 22 \\
3 \cdot 13 \\
3 \cdot 17 \\
3 \cdot 19\end{array}$ & $\begin{array}{l}2.03 \\
1.97 \\
1.91 \\
3.05 \\
3.01 \\
3.08 \\
2.84\end{array}$ & $\begin{array}{l}1.95 \\
1.90 \\
1.81 \\
2.96 \\
2.91 \\
2.99 \\
2.66\end{array}$ & $\begin{array}{l}2 \cdot 35 \\
2.00 \\
2.01 \\
3 \cdot 56 \\
3 \cdot 35 \\
3.40 \\
3.58\end{array}$ & $\begin{array}{l}1 \cdot 13 \\
1 \cdot 35 \\
1 \cdot 57 \\
2 \cdot 53 \\
2 \cdot 43 \\
3 \cdot 15 \\
3 \cdot 11\end{array}$ & $\begin{array}{l}1.08 \\
1.17 \\
1.44 \\
2.17 \\
1.86 \\
3.00 \\
2.88\end{array}$ \\
\hline
\end{tabular}




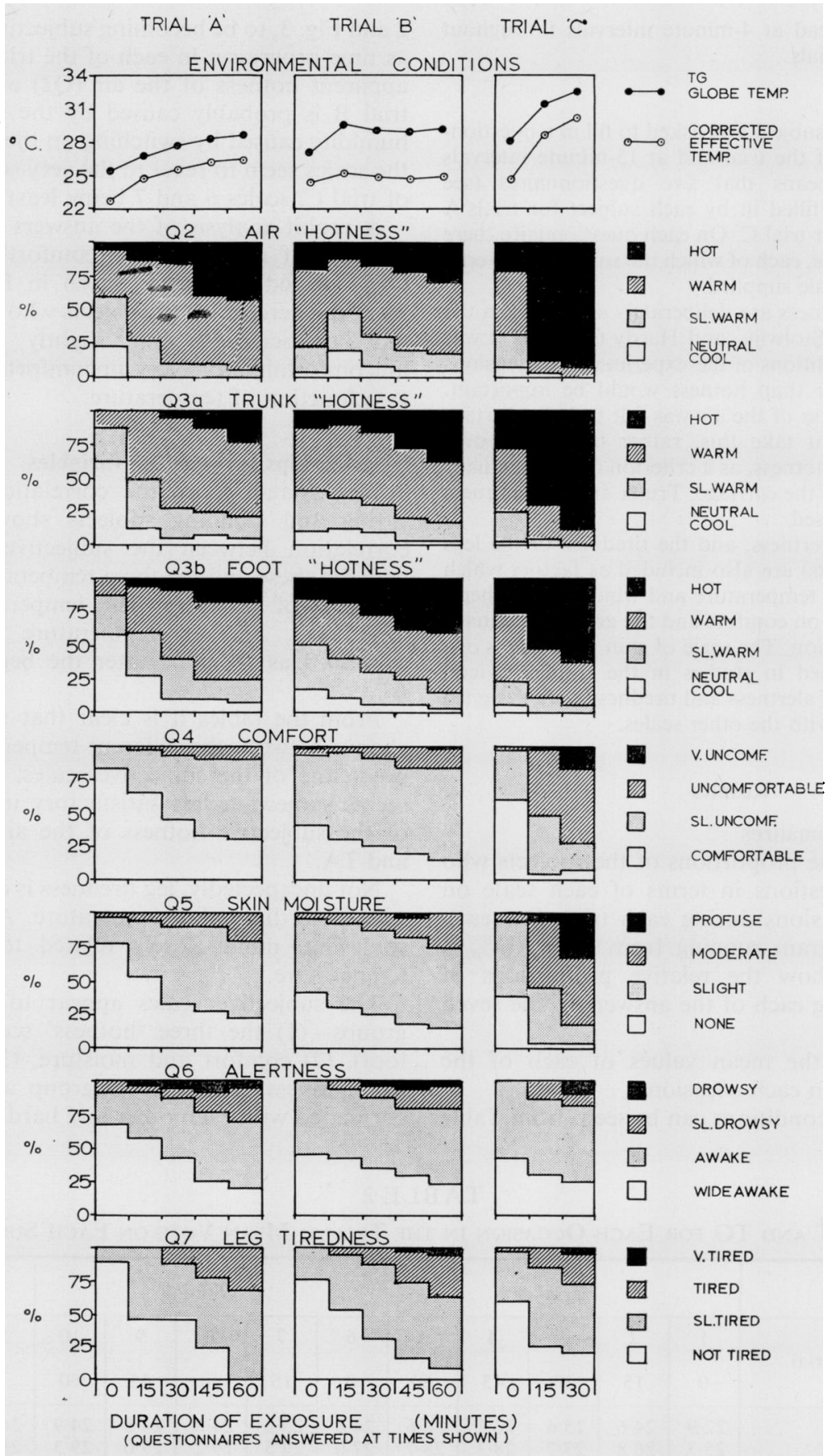

FIG. 3. Distribution of responses to each question expressed as a percentage of number of responses at each time.

the third group at all. The comfort/moisture group is reasonably correlated with both other groups and its two components are well correlated with each other. The third group constitutes the scales most affected by time.

The general picture given by the zero-order correla- 

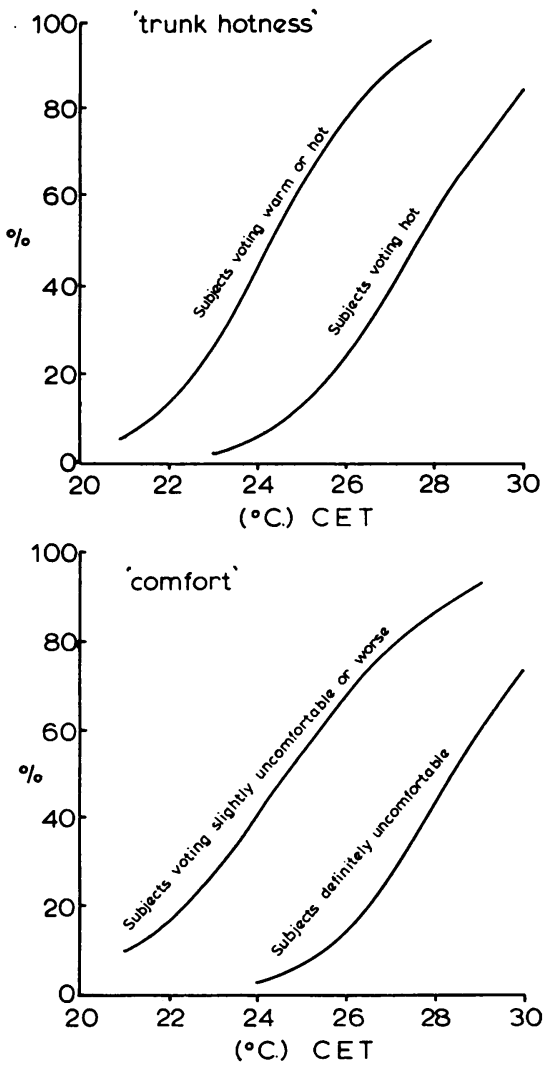

FIG. 4. Probit analysis of variation of hotness and comfort with CET.

tion matrices of the subjective scales was borne out by a contingency analysis.

A factor analysis was made of all the data in the survey, including all the available variables. The purpose of this analysis was to investigate the interrelations between the variables and try to account for the observed covariances in terms of a much smaller number of hypothetical variables or factors. The number of factors is determined by using the smallest number such that the partial correlation coefficients between all the original variables after eliminating the effects of the factors are zero.

The most important factor (that is, the factor accounting for the most variation) in the data set was temperature. The next factor was their subjective assessment of hotness, of both themselves and their surroundings, and was uncorrelated with the temperature factor. Other important factors were the physical size of the subject, the duration of the experiment, the age of the subject, and a combination of clothing and crowding. Although sitting and standing subjects were taken separately in the analysis, they each yielded similar factors in the same order.

\section{Prediction of comfort from other variables}

It is clear from the correlation matrices that in the present conditions comfort is a function of more than simple hotness. Indeed comfort is well correlated with all the subjective scales and, in particular, with skin moisture.

A detailed regression analysis of the data was made to determine which variables are important in the determination of the comfort of the subjects. In this analysis all the data were used, i.e., 17 variables for the standing subjects and 16 for the sitting. This took account not only of the questionnaire results but also of age, height, weight, sex, clothing levels, density of occupation, and the mean globe temperature recorded in the previous 10 minutes. Each variable was in turn regressed with comfort, and the best single variable was determined. The same process was repeated with all possible pairs of variables to obtain the best pair, and, similarly, for the best three, four, etc. variables, until no significant improvement was obtained by the addition of a further variable.

TABLE 3

CORrelation MatriX for Sitting Subjects

\begin{tabular}{|c|c|c|c|c|c|c|c|c|c|}
\hline & $\begin{array}{l}\text { Air } \\
\text { hotness }\end{array}$ & $\begin{array}{c}\text { Trunk } \\
\text { hotness }\end{array}$ & $\begin{array}{c}\text { Foot } \\
\text { hotness }\end{array}$ & Comfort & Moisture & Alertness & $C E T$ & $T G$ & $T \boldsymbol{A}$ \\
\hline $\begin{array}{l}2 \text { Air hotness } \\
\text { 3a Trunk hotness } \\
\text { 3b Foot hotness } \\
4 \text { Comfort } \\
5 \text { Moisture } \\
6 \text { Alertness } \\
\text { CET } \\
\text { TG } \\
\text { TA } \\
\text { Time }\end{array}$ & $\begin{array}{r}1.00 \\
0.73 \\
0.53 \\
0.47 \\
0.48 \\
0.17 \\
-0.50 \\
-0.39 \\
-0.47 \\
-0.23\end{array}$ & $\begin{array}{r}1.00 \\
0.73 \\
0.55 \\
0.55 \\
0.22 \\
-0.53 \\
-0.56 \\
-0.56 \\
-0.28\end{array}$ & $\begin{array}{r}1.00 \\
0.50 \\
0.50 \\
0.36 \\
-0.51 \\
-0.57 \\
-0.55 \\
-0.28\end{array}$ & $\begin{array}{r}1.00 \\
0.58 \\
0.40 \\
-0.50 \\
-0.51 \\
-0.51 \\
-0.23\end{array}$ & $\begin{array}{r}1.00 \\
0.27 \\
-0.56 \\
-0.57 \\
-0.58 \\
-0.22\end{array}$ & $\begin{array}{r}1.00 \\
-0.22 \\
-0.26 \\
-0.22 \\
-0.28\end{array}$ & $\begin{array}{l}1.00 \\
0.88 \\
0.94 \\
0.24\end{array}$ & $\begin{array}{l}1.00 \\
0.94 \\
0.33\end{array}$ & $\begin{array}{l}1.00 \\
0.18\end{array}$ \\
\hline
\end{tabular}


TABLE 4

Correlation Matrix for Standing Subjects

\begin{tabular}{|c|c|c|c|c|c|c|c|c|c|c|c|c|c|}
\hline & & & $\underset{\text { hotness }}{\text { Air }}$ & $\begin{array}{c}\text { Trunk } \\
\text { hotness }\end{array}$ & $\begin{array}{c}\text { Foot } \\
\text { hotness }\end{array}$ & Comfort & Moisture & Alertness & $\begin{array}{l}\text { Leg } \\
\text { tiredness }\end{array}$ & CET & $T G$ & $T A$ & Time \\
\hline $\begin{array}{l}2 \text { Air } 1 \\
\text { 3a Tru } \\
3 \text { b Foc } \\
4 \text { Com } \\
5 \text { Mois } \\
6 \text { Aler } \\
7 \text { Leg t } \\
\text { CET } \\
\text { TG } \\
\text { TA } \\
\text { Time }\end{array}$ & $\begin{array}{l}\text { hess } \\
\text { hotness } \\
\text { otness } \\
\text { t } \\
\text { e } \\
\text { s } \\
\text { iness } \\
\ldots \\
\ldots \\
\ldots \\
\ldots\end{array}$ & $\begin{array}{l}\ldots \\
\ldots \\
\ldots \\
\ldots \\
\ldots \\
\ldots \\
\ldots \\
\ldots \\
\ldots\end{array}$ & $\begin{array}{r}1.00 \\
0.69 \\
0.46 \\
0.46 \\
0.40 \\
0.14 \\
0.13 \\
-0.48 \\
-0.38 \\
-0.45 \\
-0.08\end{array}$ & $\begin{array}{r}1.00 \\
0.64 \\
0.58 \\
0.49 \\
0.18 \\
0.27 \\
-0.50 \\
-0.47 \\
-0.48 \\
-0.21\end{array}$ & $\begin{array}{r}1.00 \\
0.42 \\
0.36 \\
0.17 \\
0.31 \\
-0.26 \\
-0.35 \\
-0.29 \\
-0.29\end{array}$ & $\begin{array}{r}1.00 \\
0.63 \\
0.38 \\
0.53 \\
-0.56 \\
-0.54 \\
-0.56 \\
-0.20\end{array}$ & $\begin{array}{r}1.00 \\
0.30 \\
0.39 \\
-0.60 \\
-0.56 \\
-0.58 \\
-0.19\end{array}$ & $\begin{array}{r}1.00 \\
0.42 \\
-0.10 \\
-0.12 \\
-0.10 \\
-0.23\end{array}$ & $\begin{array}{r}1.00 \\
-0.21 \\
-0.31 \\
-0.22 \\
-0.49\end{array}$ & $\begin{array}{c}1.00 \\
0.89 \\
-0.96 \\
0.06\end{array}$ & $\begin{array}{l}1.00 \\
0.91 \\
0.28\end{array}$ & $\begin{array}{l}1.00 \\
0.06\end{array}$ & 1.00 \\
\hline
\end{tabular}

TABLE 5

(A) Best N-Term Regressions on COMfort fOR StAnding Subjects

\begin{tabular}{|c|c|c|c|}
\hline $\begin{array}{c}\text { No. of } \\
\text { variables }\end{array}$ & Best $n$ variables & $\begin{array}{c}\text { Coeff. of } \\
\text { determination }\end{array}$ & $\begin{array}{c}\mathbf{P} \text { for } \\
\text { last term }\end{array}$ \\
\hline $\begin{array}{r}1 \\
2 \\
3 \\
4 \\
5 \\
6 \\
7 \\
8 \\
9 \\
10\end{array}$ & $\begin{array}{l}5 \\
5,3 a \\
5,3 a, 7 \\
5,3 a, 7, \text { TA } \\
5,3 a, 7, \text { TA, 6 } \\
\text { 5, 3a, 7, TA, 6, TIME } \\
\text { 5, 3a, 7, TA, 6, AGE, JKT } \\
\text { 5, 3a, 7, TA, 6, AGE, JKT, TIME } \\
\text { 5, 3a, 7, TG, 6, AGE, JKT, PPLE, CET } \\
\text { 5, 3a, 7, TG, 6, AGE, JKT, PPLE, CET, HT }\end{array}$ & $\begin{array}{l}38 \cdot 81 \\
49 \cdot 63 \\
57 \cdot 37 \\
60 \cdot 21 \\
61 \cdot 48 \\
62 \cdot 06 \\
62 \cdot 62 \\
63 \cdot 04 \\
63 \cdot 48 \\
63 \cdot 70\end{array}$ & $\begin{array}{l}0.001 \\
0.001 \\
0.001 \\
0.001 \\
0.001 \\
0.05 \\
0.05 \\
0.05 \\
0.05 \\
\text { NS }\end{array}$ \\
\hline
\end{tabular}

(B) Best N-Term Regressions on Comfort for Sitting Subjects

\begin{tabular}{c|l|c|c}
\hline $\begin{array}{c}\text { No. of } \\
\text { variables }\end{array}$ & Best $n$ variables & $\begin{array}{c}\text { Coeff. of } \\
\text { determination }\end{array}$ & $\begin{array}{c}\text { P for } \\
\text { last term }\end{array}$ \\
\hline 1 & 5 & $34 \cdot 1$ & 0.001 \\
2 & $5,3 a$ & $41 \cdot 3$ & 0.001 \\
3 & $5,3 a, 6$, & 46.9 & 0.001 \\
4 & $5,3 a, 6$, CET & 48.1 & 0.001 \\
5 & 5, 3a, 6, CET, AGE & 48.7 & 0.05 \\
6 & 5, 3a, 6, TG, AGE, TA & 48.9 & NS \\
\hline
\end{tabular}

Key for variable names

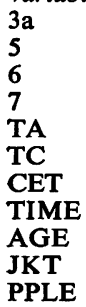

PPLE

HT
Trunk hotness

Moisture of skin

Alertness

Leg tiredness

Air temperature

Globe temperature

Corrected effective temperature

Time from start of trial

Age of subject

Whether or not subject wearing jacket or cardigan

Number of people in compartment

Height of subject 
Tables $5 \mathrm{a}$ and $\mathrm{b}$ show the results of this process for standing and sitting subjects. A consistent picture emerges. Only four terms are required, in the sitting subjects, before additional terms are adding less than $1 \%$ to the coefficient of determination. Five terms are required for a similar criterion in the standing subjects. In both cases one of the terms is a temperature term, and skin moisture, alertness, and trunk hotness are also included. In the case of the standing subjects, leg tiredness is the additional component which adds significantly to the prediction of comfort. The coefficient of determination is generally higher for the standing subjects.

For both sitting and standing subjects, statistical significance at $5 \%$ persists for more terms, but it is doubtful whether the normality of the data is reliable enough to justify taking much notice of these estimates of significance. These higher term equations include measures, other than temperatures and the subjective scales, such as age, time, and clothing.

Many studies of the effect of temperature on subjective warmth have used a scale based on that of Bedford (1936). This links warmth and comfort in a single scale. The comfort described by the subjects in this survey is of a more complex nature. Comparisons made between the answers on such a scale and the answers on a scale of the Bedford type should evidently be viewed with some caution.

\section{Relationship between comfort and hotness}

Gagge et al., in their paper (1967) in which hotness and comfort are separated, present a diagram to show the relationship between the two scales. A similar diagram for the present data is presented in Figure 5. Gagge's line is shown (discontinuous) and clearly approximates closely to the lines obtained by linear regression for the standing (upper line) and sitting subjects. Gagge suggests non-linearity in the neutral region of the 'hotness' scale. This is in good agreement with the present data in which the quadratic regression (yielding the dotted curves) is found to be a significant, if small, improvement on the linear model.

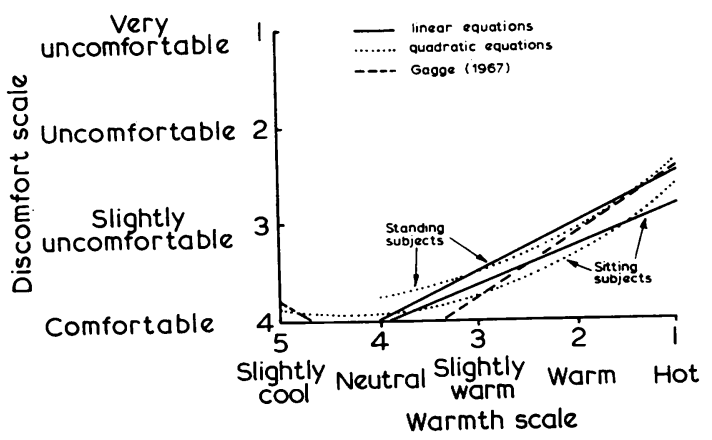

FIG. 5. Relationship between hotness and comfort.

\section{Different sub-populations}

It is possible to distinguish between the subjects in a number of ways.

'New' and 're-used' subjects In trial $A$, all subjects were new to the procedure. In trial B, 45 of the subjects had already taken part in the first trial. Of the 're-used' subjects, 34 stood and 9 sat. Of the 'new' subjects, 10 stood and 25 sat. We have compared the answers given by 'new' and 're-used' subjects in trial B to see if they differ.

The method used was first to separate sitting and standing subjects, and then to compare the average score on each scale at each time for all the 'new' subjects with the score given by the 're-used' ones. Note that on all scales the higher the score the less 'severe' the condition.

For standing subjects the scores showed a small but significant difference between the two populations in their replies to questions 2, 3a, 6 and 7. New subjects found conditions as described in questions 2 and $3 a$ to be less severe than did 're-used' subjects, but more severe for questions 6 and 7. For sitting subjects significant differences occur in the answers to questions $3 a, 3 b$, and 6 . In this case the new subjects were less dissatisfied in all three counts.

The two populations are therefore behaving in a slightly different manner. The magnitude of the differences is small, usually amounting to less than half a scale point. The clearest inference is that 're-used' subjects find conditions somewhat hotter than the new ones. This may be because conditions for trial A were generally cooler than for trial B, and the reactions of the 're-used' subjects were perhaps influenced by their previous experience.

Comparison between trial A and trial B (fresh subjects only) A comparison of average answers to questionnaires for comparable stages of trials $\mathrm{A}$ and $B$ shows that, in general, the conditions were considered better in trial $\mathbf{A}$ than in trial $\mathbf{B}$. This is in line with the higher globe temperature and greater crowding in trial $\mathbf{B}$.

The only exceptions are the answers to question 2, and of standing subjects to question 3a. Both of these may be responding to the lower CET (and humidity) in trial B.

Comparison of sitting and standing subjects A similar comparison was made between sitting and standing. subjects. All the subjects in trial A were used, and the 'new' subjects in trial $B$.

In trial $\mathrm{A}$, sitting subjects were significantly better off in terms of questions $3 \mathrm{a}, 4$, and 5 (all $\mathrm{P}<1 \%$ ). In trial $\mathrm{B}$, sitting subjects were still better off in questions 4 and $5(\mathrm{P}<5 \%)$. Again the differences were small (only 0.26 of a scale unit for question 4 , and 0.39 of a unit for question 5).

On both runs, therefore, standing subjects 
commonly found conditions somewhat more severe.

Clothing level A contrast was made between the severity of the conditions as assessed by 'lightly' and 'heavily' clad subjects.

There were insufficient standing subjects in trial A to make a comparison. In trial B there was little difference between the two weights of clothing. Lightly clad standing subjects were marginally better off in trial $\mathbf{C}$.

For sitting subjects conditions in the first two trials (A and B) were more favourable for subjects without jackets. In trial $\mathrm{C}$, subjects with jackets seemed to be better off.

Conditions were changing very fast in trial C. It may be that the insulative effect of the extra clothes helped to delay the effect of the high temperatures for sitting subjects. It can be said, however, that the overall physical effect of clothing weight was unimportant in all cases.

Men and women A comparison between men and women is made more difficult because there were relatively few female subjects. Of these, 9 out of 12 were sitting in trial $A$ and 8 out of 13 were standing in trial B. This means that a contrast can be made only between the sitting subjects in trial $A$ and the standing subjects in trial B. There is one additional problem, that the male/female split is confounded with differences in clothing particularly, and also age, weight, and height.

Ignoring these limitations, a male/female contrast on the sitting subjects in trial A shows no effect except that the men counted themselves half a scale point more 'alert' $(P=0.005)$. A male/female contrast on the standing subjects in trial $\mathrm{B}$, however, shows that the females were 'hotter' in all respects (air, trunk, and feet) by about half a scale point. For the 'air' votes this difference was $P<0.02$ and for trunk and foot votes $P<0.001$.

\section{Discussion}

Effect of temperature on comfort and hotness The data obtained from the trials are well suited to an appraisal of the effect of temperature on the subjective impressions of the subjects. This is demonstrated by the factor analyses which show temperature and subjective hotness to be the major variables.

The probit analysis (Fig. 4) gives a 20th percentile for slight discomfort of $22 \cdot 3^{\circ} \mathrm{C} \mathrm{CET}$. This is in good agreement with Bell and Watts' temperature limit of $21.8^{\circ} \mathrm{C}$ CET. For the 40th percentile a further $1.7^{\circ} \mathrm{C}$ CET can be added. Again this agrees well with the Bell and Watts recommendation of $2^{\circ} \mathrm{C}$ CET.

Definite discomfort (answer 'uncomfortable' or 'very uncomfortable' to question 4) has a 20th percentile at $26.6^{\circ} \mathrm{C} \mathrm{CET} \mathrm{and} \mathrm{a} \mathrm{40th} \mathrm{percentile} \mathrm{at}$ $27.9^{\circ} \mathrm{C}$. The $20 \%$ limit for subjective 'warmth' and 'hotness' are $22.7^{\circ} \mathrm{C}$ and $25.7^{\circ} \mathrm{C}$. These are similar to those for 'slight discomfort' and 'discomfort'.

Subjective reactions might be expected to lag somewhat behind the instantaneous temperature. The temperatures in these trials were generally rising. This may have caused the limits deduced from them to be somewhat higher than those which would be expected for a more stable temperature regime.

The results suggest that the use of CET is unnecessary and that the simpler measures TG or TA seem to be just as good. However, the effect of air movement is neglected in these data. In applying the results to situations where there was appreciable air movement, some allowance for its effects, such as that in the CET index, would have to be made.

The analysis of different sub-populations suggests that definite differences exist in the population divided in the ways described. But the differences are generally small. No particular sub-population seems sufficiently different to warrant the setting of standards around their particular requirements.

An important question to be answered is: 'How long can passengers be left in the conditions of the trials?'

An answer to this question requires a value judgement to be made. What proportion of the passengers can we afford to have uncomfortable or hot before conditions become untenable?

First let us suggest that no more than $10 \%$ of the passengers should be uncomfortable and no more than $25 \%$ should be 'hot' (queston 3a). From Fig. 3 it appears that these limits are not exceeded in trial A. In trial B they are passed after about 30 minutes and in trial $\mathrm{C}$ almost as soon as the trial began. In terms of temperature, probit analysis suggests a globe temperature limitation of $29^{\circ} \mathrm{C}$.

Let us now make less stringent limitations and prescribe a criterion of less than $25 \%$ of passengers experiencing discomfort and less than $50 \%$ experiencing hotness. We can see from Fig. 3 that these conditions are not surpassed in trials $\mathbf{A}$ or $\mathbf{B}$. Probit analysis suggests that about 10 minutes is the maximum time that can be allowed in the conditions of trial $\mathrm{C}$. For these criteria, $30-31^{\circ} \mathrm{C}$ is the limit on globe temperature.

The effects on the tiredness of the legs of standing subjects seems to be more dependent on time than on temperature. The generally higher temperatures in the later trials seem to exaggerate the effect of time, but this might as well be a time-of-day effect. It does not seem that leg tiredness is an overriding consideration.

\section{Conclusions}

The trials described simulate a number of adverse 
situations which could affect the comfort of train passengers. The results suggest that the limit for comfort proposed by Bell and Watts (1971) is reasonable, but that temperatures some 3 or $4^{\circ} \mathrm{C}$ CET higher can be tolerated without undue discomfort. In terms of globe temperature, there is a limit of some $30^{\circ} \mathrm{C}$ at which conditions become generally intolerable.

The following recommendations may be made regarding the use of the High Density Rolling Stock under test:

(1) If there is a power failure in warm conditions, crowded trains should be evacuated as soon as possible, and certainly no more than 10 minutes after the failure, otherwise extreme discomfort will be inflicted on the passengers. The physiological limit for safety recommended by Bell and Watts is a CET of $30 \cdot 6^{\circ} \mathrm{C}$. This will be reached in less than 20 minutes.

(2) An undesirable, if not dangerous, level of discomfort will be experienced by passengers in ventilated but crowded trains after 30 minutes. Uncrowded trains will not give rise to exceptionally uncomfortable conditions even if the ventilation fails. It should be pointed out, however, that a higher outside air temperature or heat gain from the sun will certainly make the situation worse.

(3) In any case it is recommended that the globe temperature in a carriage should not exceed $30^{\circ} \mathrm{C}$.

The authors are indebted to the engineers of British Rail for their assistance in the course of the trials, and to the members of British Rail clerical and administrative staff who took part as subjects.

\section{References}

Bedford, T. (1936). The Warmth Factor in Comfort at Work. Medical Research Council Industrial Health Research Board Report No. 76. Medical Research Council, London.

Bell, C. R., and Watts, A. J. (1971). Thermal limits for industrial workers. British Journal of Industrial Medicine, 28, 259-264.

Gagge, A. P., Stolwijk, J. A. J., and Hardy, J. D. (1967). Comfort and thermal sensations and associated physiological responses at various ambient temperatures. Environmental Research, 1, 1-20.

Nicol, J. F. (1973). An analysis of some observations of thermal comfort in Roorkee, India and Baghdad, Iraq. (Submitted for publication.)

Received for publication March 15, 1973

Accepted for publication May 14, 1973

Appendix A - see overleaf. 


\section{APPENDIX A}

\section{Sample questionnaire}

\section{Question}

1. Are you standing or sitting?

$$
\begin{aligned}
& \text { Standing } \\
& \text { Sitting }
\end{aligned}
$$

2. How does the air seem to you?

Hot
Warm
Slightly warm
Neutral
Slightly cool
Cool
Cold

3. How do your trunk and feet feel?

4. How comfortable are you?

5. How moist is your skin?

6. How alert are you generally?
Hot

Warm

Slightly warm

Neutral

Slightly cool.

Cool

Cold

Comfortable

Slightly uncomfortable

Uncomfortable

Very uncomfortable

Not at all

Slightly

Moderately

Profusely

Wideawake

Awake

Slightly drowsy

Drowsy
Place one tick in the appropriate box of each set Score

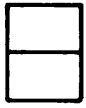

1

2

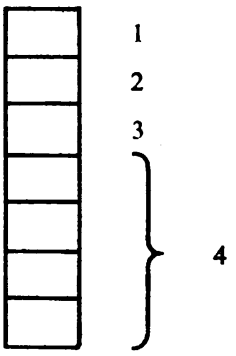

(a) Trunk

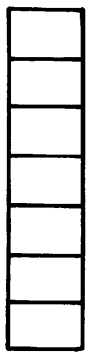

1

2

3
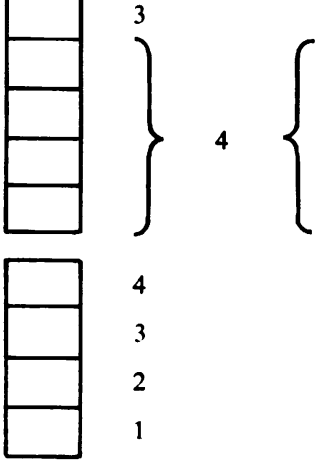

4

3

2

1

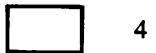

4

3

2

1

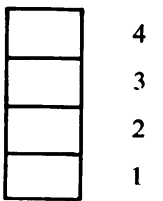

Only standing subjects to answer this question

7. How are your legs?

Not tired

Slightly tired

Tired

Very tired 